\section{Case Reports in Oncology}

Case Rep Oncol 2019;12:807-813

DOI: $10.1159 / 000503879$

Published online: October 29, 2019

(C) 2019 The Author(s)

Published by S. Karger AG, Basel

www.karger.com/cro

This article is licensed under the Creative Commons Attribution-NonCommercial 4.0 International License (CC BY-NC) (http://www.karger.com/Services/OpenAccessLicense).

Usage and distribution for commercial purposes requires written permission.

\title{
Hypofractionated Stereotactic Radiation Therapy for Metastatic Adenocarcinoma ex Goblet Cell Carcinoid of the Appendix: Case Report and Literature Review
}

\author{
Joseph W. Clyde Alan W. Katz \\ Department of Radiation Oncology, University of Rochester Medical Center, \\ Rochester, NY, USA
}

\section{Keywords}

Adenocarcinoma ex goblet cell carcinoid · Appendiceal tumors · Hypofractionated stereotactic radiation therapy · Oligometastases

\begin{abstract}
Adenocarcinoma ex-goblet carcinoid (ADA ex-GCC) is a rare and aggressive subtype of goblet cell carcinoid, a distinct tumor of the appendix characterized by both neuroendocrine and glandular differentiation. Patients often present with chronic abdominal pain or symptoms of acute appendicitis. Right hemicolectomy is the primary mode of treatment, and prophylactic salpingo-oophorectomy and hysterectomy is recommended in post-menopausal women due to the tumor's propensity of transcoelemic spread, especially to the ovaries. In this case report, we describe a patient with ADA ex-GCC who was found to have oligometastic disease in the pelvis and treated with hypofractionated stereotactic body radiation therapy (HSRT). She initially underwent a right hemicolectomy followed by adjuvant capecitabine four years prior when her tumor was incidentally discovered on colonoscopy. She subsequently had a salpingo-oophorectomy for gynecologic tract metastatic disease and declined further chemotherapy. The patient was again discovered to have oligometastatic disease in the right pelvis adjacent to the rectum on a Gallium-68 dotatate PET/MRI, and was subsequently treated with HSRT to $39 \mathrm{~Gy}$ in $6.5 \mathrm{~Gy}$ daily fractions. The patient tolerated her radiation course without notable radiation-related toxicity, and she remains without disease progression nine months later.
\end{abstract}




\section{Introduction}

Adenocarcinoma ex-goblet cell carcinoid (ADCA ex-GCC) is a poorly differentiated, aggressive subtype of goblet cell carcinoid with both neuroendocrine and glandular differentiation unique to the appendix [1]. This rare tumor has no known risk factors, and is more common in females with a median age of presentation in the fifth or sixth decade of life [2]. Patients often present with symptoms of acute appendicitis or chronic abdominal pain. These tumors have a propensity for peritoneal and pelvic transcoelomic dissemination, especially to the ovaries [2-7]. The natural history of ADCA ex-GCC is poor with one case series reporting 3- and 5 -year survival of 17 and $0 \%$ respectively [2]. Treatment with right hemicolectomy is recommended in all cases and prophylactic salpingo-oophorectomy and hysterectomy is recommended in post-menopausal women. There is little data on adjuvant therapy or treatment of recurrent or metastatic disease.

In this report, we describe a patient with ADCA ex-GCC initially treated with a right hemicolectomy followed by adjuvant capecitabine with subsequent resection of metastatic disease in the gynecologic tract followed years later with hypofractionated stereotactic radiation therapy (HSRT) to a right pelvic oligometastatic recurrence.

\section{Case Report}

A 57 year old female was found to have an ulcerated lesion at the appendiceal orifice on routine colonoscopy in February 2015. Biopsy showed poorly differentiated adenocarcinoma with signet ring cell features, and in April 2015 she underwent a right hemicolectomy. Pathology revealed an adenocarcinoma ex goblet cell carcinoid, $6 \mathrm{~cm}$ in size involving the serosal surface of the appendix and wall of cecum (pT4a) with 2/34 lymph nodes positive (pN1). Immunostains were positive for synaptophysin and chromogranin. The patient had an uncomplicated postoperative course and received adjuvant Xeloda from May to November 2015.

In July 2016, elevated chromogranin A was present, and MRI of the abdomen in August 2016 was negative. Transvaginal ultrasound in September 2016 revealed a $4.2 \times 3.1 \times 3.7 \mathrm{~cm}$ left adnexal mass. The patient underwent a left salpingo-oophorectomy and pathology was consistent with metastatic appendiceal adenocarcinoma ex goblet cell carcinoid to the ovary, fallopian tube, round and infundibular ligaments, and one pelvic lymph node.

The patient was followed with no evidence of further recurrence until December 2018 when CT of the abdomen showed enlarging $3 \mathrm{~cm}$ mass to the right of the rectum, posterior to the vaginal cuff. The patient's chromogranin A was increasing and she began complaining of right-sided abdominal pain. A Gallium-68 dotatate PET/MRI in January 2019 revealed $3.2 \mathrm{~cm}$ soft tissue lesion to the right of the rectum with a standardized uptake value (SUV) of 4 consistent with a somatostatin receptor positive tumor (Fig. 1). The patient was referred for radiation therapy. The ExacTrac patient positioning platform (BrainLab AG, Heimstetten, Germany) was used for immobilization. Treatment planning was performed using Eclipse (Varian Medical Systems, Palo Alto, CA, USA). Goal was $\geq 95 \%$ of the PTV volume getting $100 \%$ of the prescription dose. Dynamic conformal arcs were used to deliver $39 \mathrm{~Gy}$ in six 6.5 Gy daily fractions using 6-MV photons (Fig. 2). Initial follow up GA-68 scan in May 2019 showed decreases in mass and SUV. The most recent dotatate scan in August 2019 showed that the lesion was stable in size and SUV with no other areas of hypermetabolic activity (Fig. 3). The patient tolerated radiation well with no appreciable signs of toxicity. 


\section{Discussion}

The first appendiceal tumors with both neuroendocrine and glandular differentiation were described in 1969 [7]. Several subsequent reports have described this unique entity and have ascribed to it various designations including: goblet cell carcinoid, mixed crypt cell carcinoma, adenocarcinoid-goblet cell type, and microglandular goblet cell carcinoma [1]. These tumors are thought to arise from pluripotent intestinal epithelia crypt-based stem cells and represent a continuum of goblet cell carcinoid tumors (GCCs) with varying amounts of adenocarcinoma. The adenomatous component can have multiple histologic components including signet-ring cell, mucinous, glandular, and solid components [3].

The age-adjusted annual incidence of appendiceal malignancies was reported to be 0.12 cases per million [8]. GCC tumors consist of only 5\% of all appendiceal neoplasms and the ADCA ex-GCC represents an even smaller proportion of the GCCs, found to make up only 7\% of GCC cases in one series [3, 9]. GCC tumors tend to present in the fifth to sixth decade of life, intermediate to the median age of presentation for the malignant carcinoids (fourth decade) and adenocarcinoma of the appendix (seventh decade). The reported male to female ratio for all types of GCCs has varied in the literature with some case series reporting no sex predilection and others reporting a female predominance $[1,8]$. A more recent case series of $77 \mathrm{pa}-$ tients with ADCA ex-GCC has reported a strong predilection for females with a F:M ratio of 3:1 [2].

For low grade or well-differentiated GCC, the most common clinical presentation is similar to acute appendicitis; however, chronic abdominal pain is more commonly seen as the presenting symptom in the high-grade ADCA ex-GCC [3]. As the name ex-goblet cell carcinoid implies, these tumors are distinct from carcinoid tumors. Consequently, no patients have been reported to have carcinoid syndrome, and urinary 5HIAA levels in these patients are usually within normal limits [10].

Metastasis to the ovaries is well-documented in GCCs. Several series have reported that roughly half the metastases in women were to the ovaries with one study reporting that $83 \%$ of females who had stage IV disease presented with ovarian masses [1, 3-6]. Abdominal/pelvic carcinomatosis is common (77\%) in stage IV disease with regional spread to serosal surfaces and peritoneum. Metastasis to the liver or lungs is rare [2].

The natural history of GCC is intermediate between carcinoids and adenocarcinomas of the appendix. Pure, well-differentiated GCCs still have a very good survival rate, while ADCA ex-GCC has a poor prognosis. The 5-year survival of patients with the poorly differentiated adenocarcinoma type has been was reported to be between 0 and $32 \%[2,3,11]$. Young age, advanced stage, and perineural invasion has been found to be correlated with poor survival on multivariate analysis.

Treatment recommendations are similar to adenocarcinomas rather than classical carcinoids. The primary mode of treatment is surgical resection. There is general consensus that a right hemicolectomy is appropriate for more aggressive phenotypes such as ADCA ex-GCC, as supported by a SEER review [12]. Patients may also benefit from peritoneal exploration, and prophylactic salpingo-oophorectomy and hysterectomy is often recommended for postmenopausal women. Evidence regarding adjuvant treatment is lacking, though most authors recommend standard chemotherapy used for adenocarcinomas such as FOLFOX/FOLFIRI [1]. One retrospective review reported a non-significant survival advantage with adjuvant 5FU and leucovorin, and a few series describe achieving temporary control with intraperitoneal chemotherapy in selected individuals for aggressive cytoreduction $[3,6]$. 
Patients should have long-term follow up as recurrences of GCCs have been noted as long as 16 years after initial diagnosis, although there is very little data on the more aggressive ADCA ex-GCC type [13]. The most common sites of recurrence were peritonealized soft tissue and pelvic organs including the ovaries and rectum. Plasma chromogranin A has been used as a biomarker, and proved to be of benefit in the present case [14].

There are retrospective reviews on the use of stereotactic radiation therapy to treat recurrent and oligometastatic abdominopelvic tumors with good local control rates and acceptable toxicity [15]. There is a paucity of data, however, on radiation therapy in the treatment of GCCs.

In this report, we describe the long-term survival of a patient who is currently alive without evidence of progression of disease over four and a half years following hemicolectomy for an ADCA ex-GCC, three years post salpingo-oophorectomy for gynecologic tract metastatic disease, and seven months post stereotactic body radiation therapy for metachronous oligometastatic disease in the pelvis. This case is the first published report we are aware of demonstrating successful treatment of metastatic ADCA ex-GCC using HSRT. If generalizable, it would suggest that HSRT should be considered as a safe and effective modality in treating oligometastatic high grade ADCA ex-GCC tumors.

\section{Acknowledgements}

The authors thank Mrs. Laura Finger for editorial assistance.

\section{Statement of Ethics}

Our Institutional Research Subject Review Board does not require informed consent from patients for a case report.

\section{Disclosure Statement}

The authors declare no conflicts of interest.

\section{Funding Sources}

The authors did not receive any funding for this case report.

\section{Author Contributions}

JWC drafted the manuscript. AWK contributed to the radiotherapy planning and provided writing assistance. Both authors read and approved the final manuscript. 


\section{References}

1 Roy P, Chetty R. Goblet cell carcinoid tumors of the appendix: an overview. World J Gastrointest Oncol. 2010 Jun;2(6):251-8.

2 Reid MD, Basturk O, Shaib WL, Xue Y, Balci S, Choi HJ, et al. Adenocarcinoma ex-goblet cell carcinoid (appendiceal-type crypt cell adenocarcinoma) is a morphologically distinct entity with highly aggressive behavior and frequent association with peritoneal/intra-abdominal dissemination: an analysis of 77 cases. Mod Pathol. 2016 Oct;29(10):1243-53.

3 Taggart MW, Abraham SC, Overman MJ, Mansfield PF, Rashid A. Goblet cell carcinoid tumor, mixed goblet cell carcinoid-adenocarcinoma, and adenocarcinoma of the appendix: comparison of clinicopathologic features and prognosis. Arch Pathol Lab Med. 2015 Jun;139(6):782-90.

4 Tang LH, Shia J, Soslow RA, Dhall D, Wong WD, O’Reilly E, et al. Pathologic classification and clinical behavior of the spectrum of goblet cell carcinoid tumors of the appendix. Am J Surg Pathol. 2008 Oct;32(10):1429-43.

5 Varisco B, McAlvin B, Dias J, Franga D. Adenocarcinoid of the appendix: is right hemicolectomy necessary? A meta-analysis of retrospective chart reviews. Am Surg. 2004 Jul;70(7):593-9.

6 Pham TH, Wolff B, Abraham SC, Drelichman E. Surgical and chemotherapy treatment outcomes of goblet cell carcinoid: a tertiary cancer center experience. Ann Surg Oncol. 2006 Mar;13(3):370-6.

7 Gagné F, Fortin P, Dufour V, Delage C. [Tumors of the appendix associating histologic features of carcinoid and adenocarcinoma]. Ann Anat Pathol (Paris). 1969 Oct-Dec;14(4):393-406. French.

8 McCusker ME, Coté TR, Clegg LX, Sobin LH. Primary malignant neoplasms of the appendix: a populationbased study from the surveillance, epidemiology and end-results program, 1973-1998. Cancer. 2002 Jun;94(12):3307-12.

9 McGory ML, Maggard MA, Kang H, O'Connell JB, Ko CY. Malignancies of the appendix: beyond case series reports. Dis Colon Rectum. 2005 Dec;48(12):2264-71.

10 Anderson NH, Somerville JE, Johnston CF, Hayes DM, Buchanan KD, Sloan JM. Appendiceal goblet cell carcinoids: a clinicopathological and immunohistochemical study. Histopathology. 1991 Jan;18(1):61-5.

11 Hristov AC, Young RH, Vang R, Yemelyanova AV, Seidman JD, Ronnett BM. Ovarian metastases of appendiceal tumors with goblet cell carcinoidlike and signet ring cell patterns: a report of 30 cases. Am J Surg Pathol. 2007 Oct;31(10):1502-11.

12 Shaib W, Krishna K, Kim S, Goodman M, Rock J, Chen Z, et al. Appendiceal Neuroendocrine, goblet and signetring cell tumors: A spectrum of diseases with different patterns of presentation and outcome. Cancer Res Treat. 2016 Apr;48(2):596-604.

13 Kanthan R, Saxena A, Kanthan SC. Goblet cell carcinoids of the appendix: immunophenotype and ultrastructural study. Arch Pathol Lab Med. 2001 Mar;125(3):386-90.

14 Toumpanakis C, Standish RA, Baishnab E, Winslet MC, Caplin ME. Goblet cell carcinoid tumors (adenocarcinoid) of the appendix. Dis Colon Rectum. 2007 Mar;50(3):315-22.

15 Sezen D, Gurkaynak M, Gultekin M, Cengiz M, Yildiz F, Zorlu F, et al. Robotic stereotactic body radiation therapy in patients with recurrent or metastatic abdominopelvic tumors: A single institute experience. Technol Cancer Res Treat. 2016 Feb;15(1):203-11. 


\section{Case Reports in Oncology}

Clyde and Katz: Hypofractionated Stereotactic Radiation Therapy for Metastatic Adenocarcinoma ex Goblet Cell Carcinoid of the Appendix

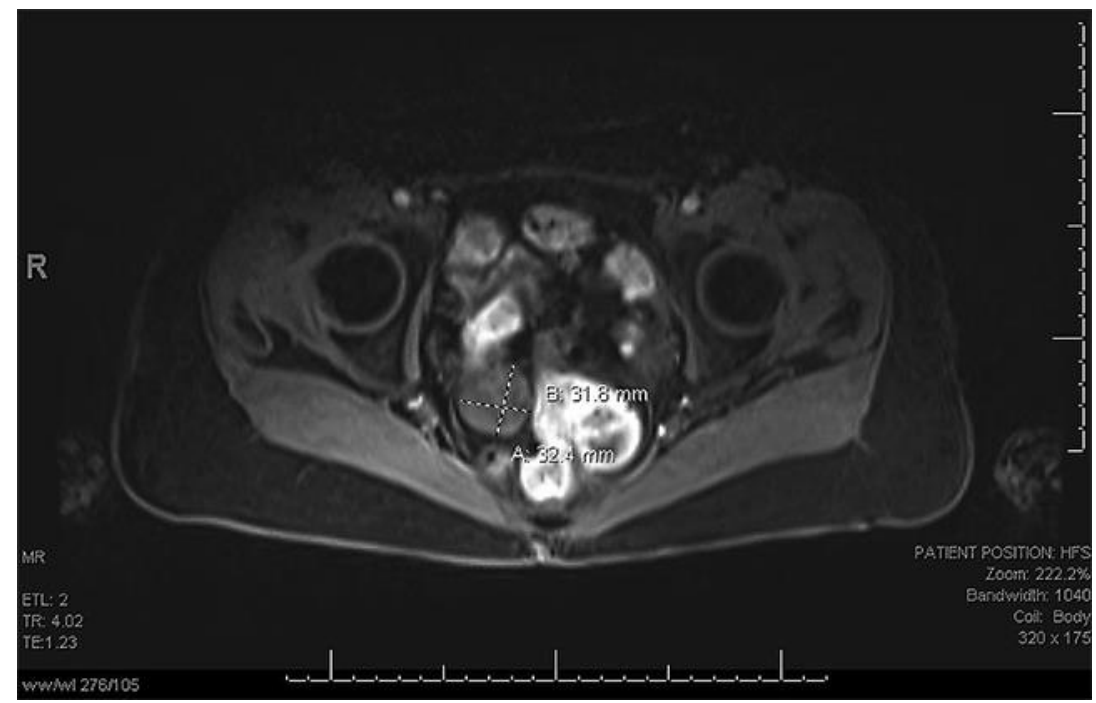

Fig. 1. A pre-treatment axial PET/MRI of the enlarging soft tissue lesion located in the right pelvis adjacent to the rectum measuring $3.2 \times 3.2 \mathrm{~cm}$.

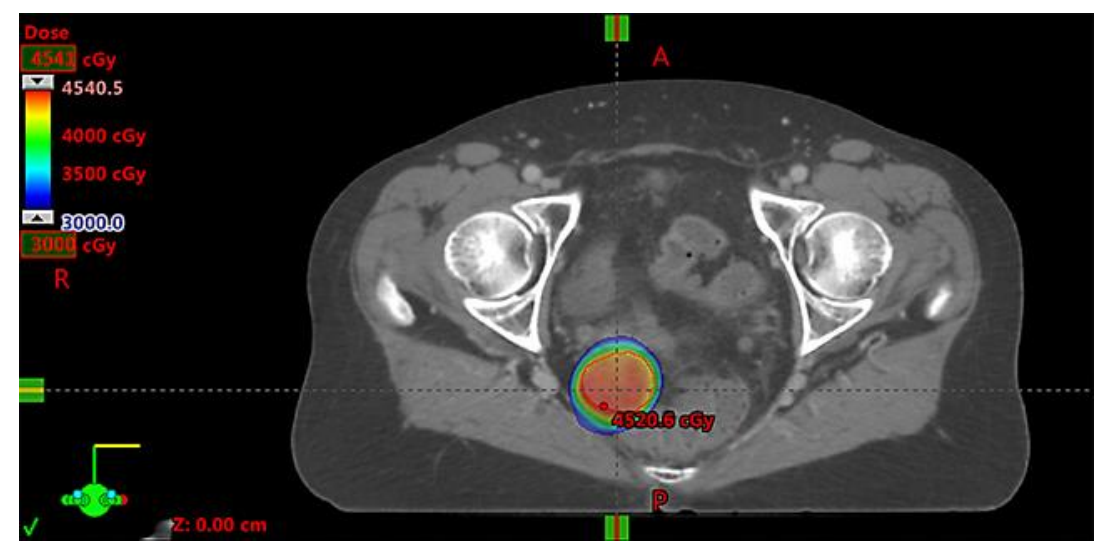

Fig. 2. Hypofractionated stereotactic radiation therapy plan of recurrent oligometastatic ADCA ex-GCC. 


\section{Case Reports in Oncology}

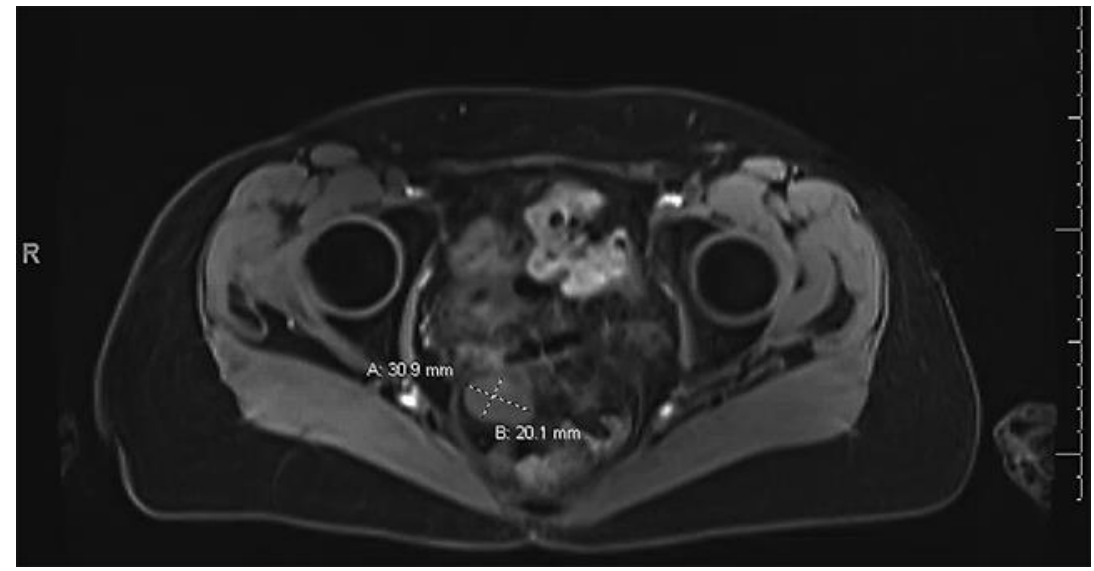

Fig. 3. A post-treatment axial PET/MRI of now stable soft tissue lesion located in the right pelvis adjacent to the rectum measuring $3.1 \times 2.0 \mathrm{~cm}$. 